\title{
Merger litigation: more recent developments
}

\author{
Matthew O'Regan*
}

\begin{abstract}
There has been a recent increase in merger-related litigation before the Competition Appeal Tribunal, driven largely by an increase in merger prohibition decisions taken by the Competition and Markets Authority. An earlier article considered several merger judgments of the CAT. The present article considers the outcomes of subsequent appeals in two of these cases, Facebook (concerning the CMA's powers to impose interim enforcement orders) and JD Sports (in which the CAT quashed the CMA's finding of a substantive lessening of competition). It also considers the outcome of two then pending challenges to CMA decisions to prohibit mergers, FNZ and Sabre. In particular, the Sabre case concerned the CMA's power to assert jurisdiction, under the share of supply test, to review a merger between two American companies in circumstances where the target company had no direct revenues from customers located in the UK. The judgments in Facebook and Sabre are likely to be of particular relevance to parties that choose not to notify voluntarily their merger to the CMA and so expose themselves to the risk of the CMA identifying and then opening an own initiative investigation into that merger; they confirm that the CMA has a broad discretion in applying the share of supply test and in adopting an IEO of broad scope to the businesses of both merger parties.
\end{abstract}

Keywords: mergers, litigation, appeals, interim enforcement order, Court of Appeal, Competition Appeal Tribunal

\section{Introduction}

An earlier article ${ }^{1}$ reviewed a number of recent judgments of the Competition Appeal Tribunal (CAT) in challenges made under section 120 of the Enterprise Act 2002 (EA 2002) to decisions made by the Competition and Markets Authority (CMA) under the mergers provisions of the EA 2002. At time of publication of that article, in December 2020, the CAT's judgment in Sabre v. Competition and Markets Authority ${ }^{2}$ was pending, as were Facebook's appeal against the CAT's judgment ${ }^{3}$ dismissing its challenge to the CMA's imposition of an interim enforcement order (IEO) in relation to its completed acquisition of GIPHY, and the CMA's application for permission to appeal the CAT's judgment in JD Sports $v$. Competition and Markets Authority, in which the CAT quashed the CMA's finding of a substantial lessening of competition (SLC) and its decision to require the merger to be unwound. ${ }^{4}$ At that time, also pending was a challenge by FNZ to the CMA's decision to prohibit and require

Barrister, St John's Chambers, Bristol

1 M. O’Regan, 'Merger litigation: recent developments in the Competition Appeal Tribunal' (2020) 19(4) Comp. Law Journal 167.

2 Case 1345/4/12/20 Sabre Corporation v. Competition and Markets Authority, application for review dated 21 May 2020, available at: https://www. catribunal.org.uk/sites/default/files/2020-06/1345_Sabre_summary_010620. pdf (accessed 13 November 2021).

3 Facebook, Inc. v. Competition and Markets Authority [2020] CAT 23, discussed in O'Regan (fn 1), pp. 174-176. the unwinding of its acquisition of GBST. ${ }^{5}$ This article provides an update on these cases.

\section{JD Sports v. CMA: the CMA is refused permission to appeal findings that it had irrationally failed to obtain sufficient information to support findings on the counterfactual and a substantial lessening of competition}

\subsection{The judgment of the Competition Appeal Tribunal}

In JD Sports, the CAT held that the CMA had failed to take reasonable steps to collect sufficient information on the effects of the COVID-19 pandemic on Footasylum, such that its findings on both the appropriate counterfactual

4 JD Sports Fashion plc v. Competition and Markets Authority [2020] CAT 24, discussed in O'Regan (fn 1), pp. 179-180 (concerning the collection of evidence) and 184-185 (concerning the finding of an SLC).

5 Case 1375/4/12/20 FNZ (Australia) Bidco Pty Ltd v. Competition and Markets Authority, application for review dated 2 December 2020, a summary of which is available at: https://www.catribunal.org.uk/sites/default/files/ 2020-12/1375_FNZ_Summary_181220_1.pdf (accessed 13 November 2021). 
and SLC did not have a sufficient evidential basis. ${ }^{6}$ It reached the same conclusion in respect of the CMA's failure to obtain information from the parties' key suppliers, Nike and adidas, on their plans to develop their own 'direct to consumer' offerings, which JD Sports argued would have provided strong and increasing competition to the merged entity. ${ }^{7}$ Accordingly, the CAT quashed the CMA's decision and remitted the merger to the CMA for further investigation. ${ }^{8}$

\subsection{Appeals from the Competition Appeal Tribunal in merger cases}

The CMA sought permission to appeal from the CAT, under section 120(6) of the EA 2002. Appeals from the CAT are governed by rules 107 and 108 of the CAT Rules. ${ }^{9}$ Permission to appeal is required from the $\mathrm{CAT}^{10}$ and, unless there are special circumstances, an application for permission to appeal will be decided without a hearing. ${ }^{11}$

An appeal from the CAT to the Court of Appeal must be on a point of law ${ }^{12}$ and the party seeking permission must identify the alleged error of law and why the CAT's approach in its judgment was erroneous. ${ }^{13}$ In deciding whether to grant permission to appeal, the CAT applies (when the appeal will be to the Court of Appeal in England and Wales) the test in CPR $52.3(6)$, i.e. it will grant permission only where it considers that the appeal would have a real prospect of success or there is some other compelling reason why the appeal should be heard. ${ }^{14}$ Where permission to appeal is refused by the CAT, the application may be renewed to the Court of Appeal, pursuant to CPR 52 and Practice Direction $52 \mathrm{D} .^{15}$

\subsection{The Competition Appeal Tribunal's ruling on permission to appeal}

The CMA argued that the CAT had failed to apply the correct legal test, to give adequate reasons and/or had disregarded relevant matters in determining that it had acted irrationally in deciding not to obtain additional information on the effect of COVID-19 on Footasylum and, from its bank, on its financial position. The CMA also argued that there were, in addition, compelling reasons why its appeal should be heard, as it considered that the CAT's judgment raised important questions on its evidence-gathering powers and obligations.

The CMA's application was refused, ${ }^{16}$ as all arguments advanced by the CMA in its application for permission to appeal had been made and considered by the CAT in its judgment, such that there was no realistic prospect of an appeal being successful. ${ }^{17}$ There was also no other compelling reason for the appeal to be heard: the CAT considered that there was no general principle of law that required clarification by the Court of Appeal (it being well established that a public authority acts irrationally if it makes a decision without having first obtained the evidence required to support it) ${ }^{18}$ and the facts of the case were both very specific and unlikely to be repeated. ${ }^{19}$

The CAT considered that, in its judgment in JD Sports, it had applied well-established legal principles to a very particular set of circumstances arising from the onset of the COVID-19 pandemic at the very end of the CMA's extended period for reviewing the JD Sports/Footasylum merger. ${ }^{20}$ It had not failed to have regard to the CMA's wide margin of appreciation in obtaining and then evaluating evidence. Rather, on two particular aspects of its inquiry, the CAT had found that the CMA had reached conclusions (that Footasylum would have remained an effective competitor absent the merger and that the likely impact of COVID-19 on the retail sector would have been neutral on different types of retailer) that were not supported by the necessary evidence; the CMA had, thereby, acted irrationally. ${ }^{21}$ Interestingly, in its ruling the CAT emphasized that 'timing constraints do not give the CMA an all-embracing power to curtail the obtaining of evidence on a particular point, if it wishes to draw final conclusions on that point'. ${ }^{22}$ Accordingly, the constraints of a merger timetable cannot be a reason not to seek further information, if the CMA would have sufficient time to take into account information submitted to it very late in its inquiry. ${ }^{23}$ In

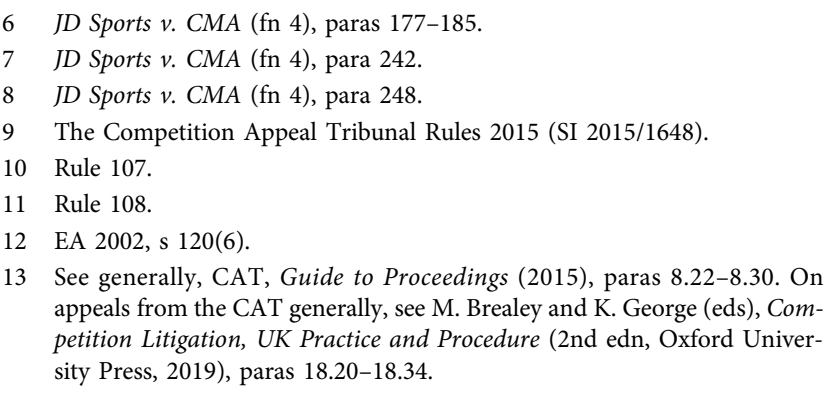

13 See generally, CAT, Guide to Proceedings (2015), paras 8.22-8.30. On appeals from the CAT generally, see M. Brealey and K. George (eds), Competition Litigation, UK Practice and Procedure (2nd edn, Oxford University Press, 2019), paras 18.20-18.34.

14 Guide to Proceedings (fn 13), para 8.28.

15 See Practice Direction 52D, para 8.1(2)(b)

16 JD Sports Fashion plc v. Competition and Markets Authority (Permission to appeal) [2020] CAT 27.

17 JD Sports v. CMA (Permission to appeal) (fn 16), para 50.

18 JD Sports v. CMA (Permission to appeal) (fn 16), para 52.

19 JD Sports v. CMA (Permission to appeal) (fn 16), para 53.

20 JD Sports v. CMA (Permission to appeal) (fn 16), paras 33 and 34

21 JD Sports v. CMA (Permission to appeal) (fn 16), paras 35-43.

22 JD Sports v. CMA (Permission to appeal) (fn 16), para 44. 
such circumstances, the CMA could not properly decline to seek additional information because it considers it would be 'futile' to do so.

The CAT also considered that the CMA's appeal did not give rise to any other compelling reason for it to be heard. Rather than developing new law on the CMA's evidence gathering obligations, its judgment merely applied, in a highly fact-specific case, the well-established principle that it is irrational for an authority, such as the CMA, to draw conclusions without having obtained the evidence properly to do so. ${ }^{24}$

\subsection{Refusal by the Court of Appeal of permission to appeal}

Having been refused permission to appeal by the CAT, the CMA renewed its application for permission before the Court of Appeal. This was unsuccessful; ${ }^{25}$ the Court of Appeal's decision to refuse permission has not been published.

On remittal, and having obtained additional evidence on the impact of COVID-19 and other market developments, the CMA again found that the merger gave rise to competition concerns and has required JD Sports to divest Footasylum, in order to unwind the merger. ${ }^{26}$

\section{FNZ v. CMA: CMA requests its decision prohibiting a merger to be quashed and remitted}

The matter in FNZ was referred back to the CMA (pursuant to section 120(5)(b) of the EA 2002) after the CMA accepted that there were 'certain procedural errors in its market share calculations as a result of the provision of inconsistent information' to it during its Phase 2 investigation. ${ }^{27}$ Accordingly, the CMA's decision on an SLC and remedy was, at its request, quashed and remitted back to it for further consideration. ${ }^{28}$

The CMA subsequently, on remittal, again found that the FNZ/GBST merger has resulted, or was expected to result, in an SLC due to horizontal unilateral effects and required FNZ to sell GBST, subject to a right to reacquire certain parts of the GBST business unrelated to the activities that gave rise to the SLC. ${ }^{29} \mathrm{FNZ}$ did not challenge this decision.

\section{Facebook: the Court of Appeal confirms that the CMA has a wide discretion in imposing an interim enforcement order}

On 13 November 2020, the CAT dismissed in its entirety Facebook's challenge to an IEO made by the CMA in relation to its completed acquisition of GIPHY and the CMA's refusal accede to several derogation requests made by Facebook, including to carve-out from specific provisions of the IEO the majority of Facebook's global business operations. Facebook appealed to the Court of Appeal. ${ }^{30}$ The Master of the Rolls, Sir Geoffrey Vos, gave the judgment of the Court, with which the Chancellor of the High Court, Sir Julian Flaux and Lord Justice Phillips agreed, rejecting Facebook's appeal in its entirety.

\subsection{Facebook's grounds of appeal}

The overall thrust of Facebook's appeal was that the CMA's approach to the IEO (which applied to Facebook's entire global business) and Facebook's requests for derogations from its requirements, in particular to 'carve-out' from it substantially all of Facebook's business, was 'inappropriate and impractical' and neither rational nor proportionate in order to preserve the GIPHY business acquired by it. ${ }^{31}$ In addition, it argued that the IEO effectively 'froze' Facebook's business activities globally and, by subjecting it to a 'slow and bureaucratic derogation procedure', was thereby incompatible with the CMA's statutory duty ${ }^{32}$ to promote competition for the benefit of consumers. ${ }^{33}$

Facebook's first ground of appeal was that the CAT had wrongly held that, under section 72 of the EA 2002 , the concept of 'pre-emptive action' is sufficiently broad to give the CMA the power to regulate any activity
23 JD Sports v. CMA (Permission to appeal) (fn 16), paras 45 and 49.

24 JD Sports v. CMA (Permission to appeal) (fn 16), paras 52 and 53.

25 See https://www.gov.uk/cma-cases/jd-sports-fashion-plc-footasylum-plcmerger-inquiry (accessed 13 November 2021).

26 CMA, Completed acquisition by JD Sports Fashion plc of Footasylum plc. Final report on the case remitted to the CMA by the Competition Appeal Tribunal (5 November 2021).

27 See https://www.gov.uk/cma-cases/fnz-gbst-merger-inquiry (accessed 13 November 2021).

28 FNZ (Australia) Bidco Pty Ltd v. Competition and Markets Authority (Remittal) (Order of 21 January 2021).
29 CMA, Completed acquisition by FNZ of GBST; Final report on the case remitted to the CMA by the Competition Appeal Tribunal on 21 January 2021 (4 June 2021).

30 It is not clear whether permission to appeal was granted by the CAT or by the Court of Appeal. No ruling on an application for permission to appeal has been published on the CAT's website.

31 Facebook, Inc. v. Competition and Markets Authority [2021] EWCA Civ 701, para 9.

32 Enterprise and Regulatory Reform Act 2013, s 25(3).

33 Facebook v. CMA (fn 31), paras 40-42. 
that has the potential to affect the competitive structure of the market during its investigation. Facebook argued that this power was limited to taking measures to protect the CMA's investigation and potential remedies that it might impose at the end of its investigation.

Facebook's second ground of appeal was that the CMA had no power, in making an IEO, to 'freeze' Facebook's existing business. It argued that, since the most 'radical' final remedy the CMA could adopt would be to unwind the merger by ordering the divestment of GIPHY, it could apply an IEO only to the existing GIPHY business.

Third, Facebook argued that, by applying the IEO to Facebook's global business, the specific obligations imposed by the IEO were 'excessively broad' and thus both irrational and disproportionate.

Fourth, Facebook argued that the CMA had made 'disproportionate' information requests in respect of Facebook's derogation requests, which, in effect, constituted a refusal to grant the derogations requested by Facebook.

\subsection{The scope of the CMA's powers to impose an interim enforcement order}

The Court of Appeal confirmed that the CMA's powers, in the event of it finding an SLC, ${ }^{34}$ are not limited to requiring divestiture of the acquired enterprise. Its powers extend to requiring the acquiring party to take action to remedy, mitigate or prevent the SLC, e.g. by reversing decisions taken following the merger with respect to its own business. ${ }^{35}$ Further, in merger cases, the CMA must act quickly to prevent 'pre-emptive action' by adopting a 'broad template' IEO in order to 'hold the ring', whilst it obtains information that may enable it to reduce the scope of the IEO, through making derogations. ${ }^{36}$ This requires the merging parties to cooperate with the CMA, which Facebook did not do: instead, it 'sat on its hands, refusing to answer the CMA's questions' relating to its requests to 'carve out' from the IEO most of Facebook's business. ${ }^{37}$ Accordingly, Facebook's difficulties were 'entirely of [its] own making' ${ }^{38}$ and it was 'the author of its own misfortune' in its entire business continuing to be bound by the IEO. ${ }^{39}$ Had Facebook properly engaged with the CMA, it would have been able to address the carve-out requests. ${ }^{40}$

The Court of Appeal considered that the threshold for the CMA making an IEO is very low: its powers under section 72 of the EA 2002 are both wide and engaged as soon as it is considering making a reference for a Phase 2 inquiry into the merger. ${ }^{41}$ Thus, an IEO may be imposed to prevent 'all kinds' 42 of 'pre-emptive action' by the merging parties that might 'alter the competitive structure of the market during the course of the CMA's investigation'. ${ }^{43}$ The CMA has a wide margin of appreciation in identifying and regulating any conduct that the merging parties might take and which might constitute pre-emptive action. ${ }^{44}$

\subsection{The proper scope of an interim enforcement order}

The CMA's ability to make an acquiring party's existing business subject to an IEO is particularly important in the case of completed mergers, where the acquiring party could discontinue those parts of its own business that compete with the target business: in such circumstances, divestiture of the target following a Phase 2 investigation in which the CMA finds an SLC would not be sufficient to restore the status quo or protect competition. ${ }^{45}$ As the CMA's remedial powers, having found an SLC, ${ }^{46}$ are not limited to requiring divestiture of the target business and may extend to requiring the acquiring party to take specified action relating to its own business, it therefore followed that the CMA could lawfully bring Facebook's existing global business within the scope of the IEO. ${ }^{47}$ Having done so, the CMA could, for the purposes of assessing Facebook's carve-out requests, ask questions on that business. ${ }^{48}$

\subsection{Derogations from an interim enforcement order}

If a merging party wishes to have the requirements of an IEO varied, it must apply to the CMA for a derogation. This requires it to cooperate with the CMA and provide to it the information it requires in order to consider the request, including by answering the CMA's reasonable questions. ${ }^{49}$ As Facebook did not do so, the CMA was

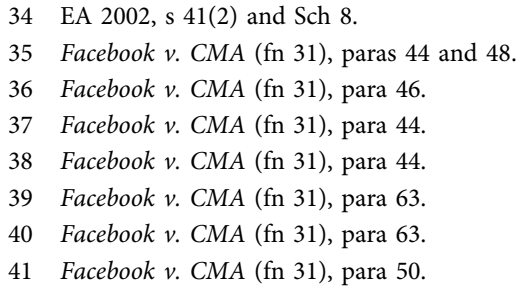

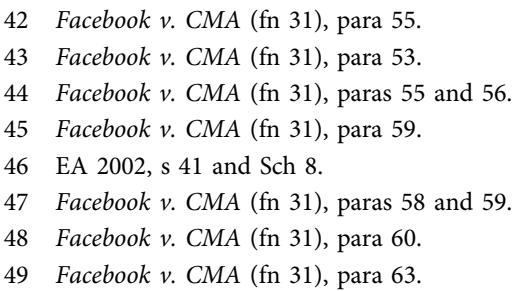

42 Facebook v. CMA (fn 31), para 55

43 Facebook v. CMA (fn 31), para 53.

5 Facebook v. CMA (fn 31), para 59.

6 EA 2002, s 41 and Sch 8

Facebook v. CMA (fn 31), para 60

Facebook v. CMA (fn 31), para 63. 
entitled not to release Facebook from specific obligations relating to the conduct of its own business, other than GIPHY. ${ }^{50}$

The Court of Appeal also upheld the CAT's finding that the CMA's requests for information were not irrational and thus were not disproportionate: the CAT had correctly applied the appropriate standard of review applicable to a challenge under section 120 of the EA 2002 to a CMA decision, i.e. whether the CMA's decision to request further information was 'manifestly without reasonable foundation', i.e. irrational. As the CMA has a wide margin of appreciation in determining, and thus requesting, the information that it requires for the purposes of a merger inquiry, including to assess a request for a derogation from an IEO, it was not for the CAT or the Court to second guess what information the CMA could ask from Facebook. ${ }^{51}$

\subsection{Commentary}

The Court of Appeal's judgment in Facebook confirms that the CMA has a wide discretion in determining the proper scope of an IEO and that it may properly impose an IEO based on its standard template IEO. Therefore, it may impose obligations on the acquiring party that concern the conduct and management of its entire global business. If that party considers that the scope of the IEO is excessively broad, and that a narrower set of obligations would be sufficient to prevent 'pre-emptive action' that might inhibit the CMA's ability to impose remedies to restore effective competition if it prohibits a completed merger, it must apply for a derogation. This requires it to cooperate with the CMA and to provide it with the information that it requires to assess the derogation request and be satisfied that it would not prevent it from imposing effective remedies following its investigation.

The CMA subsequently imposed penalties of

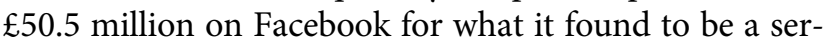
ies of deliberate and 'particularly serious and flagrant' infringements of the IEO, including by repeatedly, and without reasonable excuse, submitting to the CMA regular compliance statements that were accompanied by significant qualifications and did not provide all required information, even after the CMA had warned Facebook of its non-compliance. ${ }^{52}$

On 30 November 2021, the CMA published its Final Report into the Facebook/GIPHY merger, in which it prohibited the merger; it required Facebook to divest the GIPHY business in its entirety to a suitable buyer (including by transferring to it certain assets and personnel that have been integrated into Facebook's businesses) and to reinstate certain of GIPHY's activities that Facebook had discontinued before the IEO was made. ${ }^{53}$ This reflects the Court of Appeal's finding that the CMA's remedial powers extend beyond merely requiring divestiture of the acquired business. On 23 December 2021, Meta Platforms (as Facebook is now known), filed an application for review of the CMA's prohibition and remedy decision on both substantive and procedural grounds. $^{53 a}$

\section{Sabre v. CMA: the CAT confirms that the CMA has a wide discretion in applying the 'share of supply' test to establish jurisdiction to review a merger}

On 9 April 2020, the CMA published its Final Report into Sabre Corporation's (Sabre) anticipated acquisition of Farelogix Inc (Farelogix). ${ }^{54}$ The CMA had asserted jurisdiction to the review the merger on the basis of the share of supply test in section 23(2)(b) of the EA 2002. It found that that the merger would have resulted in an SLC on two worldwide markets, the supply of merchandising solutions to airlines and the supply of distribution solutions to airlines. It accordingly prohibited the merger, which was subsequently formally abandoned by the parties.

\subsection{The CMA's application of the share of supply test}

The CMA's exercise of jurisdiction in Sabre/Farelogix was somewhat controversial and was one of a series of decisions in which the CMA asserted jurisdiction over
50 Facebook v. CMA (fn 31), paras 63 and 64.

51 Facebook v. CMA (fn 31), paras 65-67.

52 CMA, Completed acquisition by Facebook, Inc. of GIPHY, Inc.; Decision to impose a penalty on Facebook, Inc., Tabby Acquisition Sub Inc., and Facebook UK Limited under section 94A of the Enterprise Act 2002 (20 October 2021).

53 CMA, Completed acquisition by Facebook, Inc (now Meta Platforms, Inc) of Giphy, Inc., Final Report (30 November 2021).

53a Case 1429/4/12/21 Meta Platforms, Inc. $v$ Competition and Markets Authority. A summary of Meta Platforms' application is available on the
CAT's website, at https://www.catribunal.org.uk/sites/default/files/202201/20220105_1429_Rule_14_summary_0.pdf. Whilst, in its Final Report (fn 53), the CMA found an SLC as a result of both horizontal and vertical effects, Meta Platforms does not challenge the finding of an SLC as a result of vertical effects, although it does challenge the lawfulness of the divestiture remedy (and related measures to ensure GIPHY's viability) as a remedy for the vertical SLC.

54 CMA, Anticipated acquisition by Sabre Corporation of Farelogix Inc., Final Report (9 April 2020). 
mergers between non-UK companies in which the target business had no revenue in the UK. ${ }^{55}$

In Sabre/Farelogix, the CMA established jurisdiction to review the merger by reference to the supply by Farelogix to one UK airline customer, British Airways, of services that facilitate the indirect distribution of airline content. ${ }^{56}$ In applying the share of supply test, the CMA described the relevant services on which the parties had overlapping supply in the UK as 'IT solutions to UK airlines for the purpose of airlines providing travel services information to travel agents to enable travel agents to make bookings' ${ }^{57}$ in respect of which Sabre had a pre-existing share of supply of over $25 \%$. Sabre supplied such solutions to UK airlines as part of its 'global distribution system', whilst Farelogix did so through a solution known as 'FLX', which allows airlines to create ancillary offers; in the case of British Airways, FLX services were used by it only for sales of interline segments, under interlining arrangements with OneWorld Alliance partners, including American Airlines.

However, Farelogix did not receive payments for its FLX solution from British Airways. Nevertheless, the CMA considered that Farelogix did 'derive value' from supplying these services to British Airways, and thus was making a supply of them in the United Kingdom, as: (i) its OneWorld Alliance partner, American Airlines, did pay fees to Farelogix for tickets issued by it that included a segment operated by British Airways, and (ii) Farelogix was entitled to charge British Airways a fee for tickets sold using its FLX services, although in practice it had not done so.

\subsection{Sabre's grounds of appeal}

Although the merger had been abandoned by the parties following the CMA's prohibition decision, Sabre made an application for review to the CAT under section 120 of the EA 2002, ${ }^{58}$ challenging both the CMA's assertion of jurisdiction under the share of supply test and its substantive finding of an SLC. ${ }^{59}$ However, it subsequently abandoned its challenge to the SLC finding.

55 See e.g. S. Pritchard and V. Egerton-Doyle, 'Stretch target: the long arm of UK merger jurisdiction' (2020) 19(3) Comp. Law Journal 101. The other cases considered by the authors in which the CMA had adopted an expansive approach to the application of the share of supply test were Case ME/6831/19 Anticipated acquisition by Roche Holdings, Inc. of Spark Therapeutics, Inc. (16 December 2019), which was cleared after a Phase I investigation, and Case ME/50824-19 Anticipated acquisition by Mastercard Incorporated of Parts of the Corporate Services Business of Nets A/S (3 April 2020), in which the CMA made a referral request under Article 22 of the EU Merger Regulation.

56 Sabre/Farelogix (fn 54), para 110.

57 Sabre/Farelogix (fn 54), para 28.

58 Challenges under s 120 of the EA 2002 to CMA merger decisions are made on judicial review grounds: $s$ 120(4). These are summarized in O'Regan (fn 1), pp. 169-170 and in Facebook v. CMA (fn 31), paras 55-61.
Sabre advanced four grounds of challenge to the CMA's finding that it had jurisdiction to review the merger: (i) the 'relevant description of services' against which the CMA applied the share of supply test was unlawful, given the supplies made by the parties were 'highly disparate'; (ii) the CMA erroneously found that Farelogix supplied services in the UK, by conflating supply to American Airlines with a direct supply to British Airways; (iii) the CMA erred in applying the share of supply test by relying on an increment that was 'hypothetical and vanishingly small' and by applying different and inconsistent methodologies in calculating the shares of Sabre and Farelogix; and (iv) the CMA failed to apply consistently its definition of the 'relevant description of services' to third parties. ${ }^{60}$

\subsection{Application of the share of supply test: basic principles}

The CAT identified several principles that it should apply in interpreting and applying the jurisdictional provisions of the EA 2002. It emphasized that, whilst the construction of the EA 2002 is a question of law for the CAT to determine, its application to the facts of a particular case is a matter for the CMA to determine, which the CAT may review on judicial review grounds only $^{61}$ and to the 'normal' intensity of review. ${ }^{62}$ Therefore, if the CMA's assessment of these facts involves matters of expert economic judgement, the CAT must show deference to the CMA (it being an expert authority), but where it does not do so, the CAT will review the CMA's assessment in accordance with standard principles of judicial review. ${ }^{63}$

The CAT confirmed that UK jurisdiction over a merger is based on the principle of territoriality, and requires a 'connection' or 'nexus' to the UK, through either turnover arising in the UK (the turnover test) or by goods or services being supplied in the UK (the share of supply test). ${ }^{64}$ If either test is satisfied, no further question arises as to whether international comity requires the CMA to

59 Sabre Corporation v. Competition and Markets Authority [2021] CAT 11, paras 4 and 5. A summary of Sabre's grounds of challenge is available on the CAT's website, at: https://www.catribunal.org.uk/cases/134541220sabre-corporation (accessed 13 November 2021). Its two (abandoned) grounds of challenge to the finding of an SLC were: (i) the CMA could not, correctly applying the standard of proof and on a proper assessment of the evidence, have lawfully found an SLC in relation to the merchandising market; and (ii) the finding of an SLC in relation to the distribution market was irrational and unsupported by the evidence.

60 Sabre v. CMA (fn 59), para 4

61 Sabre v. CMA (fn 59), para 85(1)-(3).

62 Sabre v. CMA (fn 59), para 85(6).

63 Sabre v. CMA (fn 59), para 85(4)-(5).

64 Sabre v. CMA (fn 59), para 86. 
decline jurisdiction in order to ensure that it does not act 'extra-territorially'. ${ }^{65}$

In terms of the CMA's application of the share of supply test, the CAT held that the selection of 'services of any description' against which to apply the test ${ }^{66}$ is a matter for the CMA's judgement and discretion; it is thus not a question of primary, objective fact and requires the CMA to assess several issues. ${ }^{67}$

The CAT emphasized that the purpose of the share of supply test is to identify mergers that, whilst not meeting the turnover test, are 'suitable for investigation' and which involve 'a degree of overlap in commercial activity ... above a certain level, so as to warrant investigation by the CMA' because there is a sufficient prospect of a competition concern arising as a result of the overlap. ${ }^{68}$ The test is not a 'market share test' and does not require the CMA to undertake a detailed, economic market share analysis. ${ }^{69}$

\subsection{Identification by the CMA of the 'relevant description of services'}

In applying the share of supply test, the CMA is required to identify goods or services of 'any description' ${ }^{70}$ In determining whether the merging parties' share of supply of such goods or services is at least $25 \%$, the CMA may apply such criterion or criteria as it considers to be appropriate. ${ }^{71}$ The CMA may also apply such criterion or criteria as it considers appropriate in determining whether goods or services may be treated as goods or services of a 'separate description'. ${ }^{72}$

In summary, Sabre argued that, in applying the share of supply test, CMA had 'reverse engineered' a 'relevant description of services' that both encompassed both parties' products, but was sufficiently narrow to ensure that their share of supply was over $25 \% .{ }^{73}$ It asserted that the description used, 'IT solutions to UK airlines for the purpose of airlines providing travel services information to travel agents to enable travel agents to make bookings', was so broad as to be 'meaningless', was not recognized by the airline industry and excluded some products with equivalent functionality. ${ }^{74}$ Accordingly, the definition of the 'relevant description of services' was 'arbitrary'. ${ }^{75}$

The CAT rejected this argument. It held that the CMA has a broad discretion in selecting the criterion, or criteria, to be used to identify services of a particular description and to distinguish them from services of a different description. ${ }^{76}$ Therefore, Sabre could only challenge the CMA's definition of the services of a 'relevant description' on the basis that it was irrational. ${ }^{77}$ Although the CAT had some concerns that the CMA had applied an iterative process in adopting a final definition of services used to apply the share of supply test, this process was neither arbitrary nor irrational, as the CMA may refine its approach to the share of supply test as its investigation progresses, including in response to submissions made by the merging and third parties. ${ }^{78}$

Taking account of the purpose of the share of supply test in identifying mergers worthy of investigation by the $\mathrm{CMA}^{79}$ the CMA was entitled to define a 'relevant description of services' that was based on the common functionality of the parties' products, even if the relevant purpose of the service in question is achieved by different means, including as part of a wider product or on a standalone basis. ${ }^{80}$ In other words, the CMA may apply the test where the parties' services 'do a sufficiently similar thing' and thus overlap, ${ }^{81}$ as they are 'commercial alternatives' ${ }^{82}$ It is not necessary for the description used by the CMA to correspond to an industry standard. ${ }^{83}$

Having defined the criteria for defining a 'relevant description of services', the CMA must then apply them uniformly to any and every service which falls for consideration by it. ${ }^{84}$ In doing, it may properly exclude 'self-supply', as self-supplied services are not offered on the open market and so do not compete with other suppliers for customers' business. ${ }^{85}$
65 Sabre v. CMA (fn 59), paras 86 and 87.

66 EA 2002, s 23(4).

67 Sabre v. CMA (fn 59), paras 88 and 89 . The issues that the CMA must take into account include: (i) how services may be characterized; (ii) whether services have features in common; (iii) whether, taking account of their commercial substance, services provided by the parties and third parties fall within the description of services used by the CMA in applying the test; (iv) what metric should be used to calculate shares of supply; and (v) how to apply those metrics to the facts of a particular case.

68 Sabre v. CMA (fn 59), paras 143 and 144.

69 Sabre v. CMA (fn 59), para 145.

70 EA 2002, ss 23(3) (in relation to the supply of goods) and 23(4) (in relation to the supply of services).

71 EA 2002, s 23(5). Such criteria may include one or more of 'value, cost, price, quantity, capacity, number of workers employed or some other criterion'.

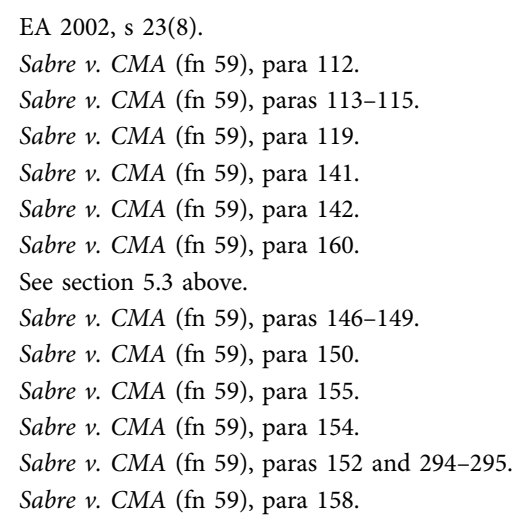




\subsection{Application of the share of supply test to the 'relevant description of services'}

Sabre argued that the CMA had erred in concluding that Farelogix supplied the 'relevant description of services' in the UK. The CMA found that Farelogix did so as it had an agreement that enabled British Airways to use Farelogix's 'FLX' services, which the CMA considered to be within the relevant description of services. ${ }^{86}$

In reaching its conclusion that Farelogix supplied these services directly to British Airways in the UK, the CMA stated that, even though there may not have been a direct contractual relationship between Farelogix and British Airways, it took account of the 'commercial reality of the existing relationships', comprising a number of different contracts, between Farelogix, American Airlines and British Airways in respect of British Airways' marketing of interline segments under its interlining arrangements with American Airlines. ${ }^{87}$ In the CMA's view, the FLX services provided by Farelogix enabled British Airways to provide travel services information and to market interline segments, such that it used and received a supply of FLX services from Farelogix. ${ }^{88}$ Therefore, because British Airways is a UK airline, the merger had a 'relevant UK nexus' and, therefore, Farelogix was supplying its FLX services in the UK. ${ }^{89}$

Contrary to Sabre's submission, the CAT held that the CMA's finding that Farelogix supplied FLX services to British Airways raised no question of the construction of section 23 of the EA 2002 or any other error of law: the only question for the CAT to consider was whether the CMA's finding was Wednesbury unreasonable, i.e. irrational, on a standard judicial review basis. ${ }^{90}$ Following a detailed review of the terms of the various agreements relied on by the CMA and the booking processes, the CAT concluded that the CMA's findings were supported by the facts, and so were ones that it was entitled to make, and in any event were not irrational. ${ }^{91}$

The CAT then went on to consider Sabre's argument that the CMA had erred in identifying an increment in the share of supply. In its Final Report, the CMA had based its calculations of shares of supply on the value derived from the supply of the 'relevant description of services' to UK airlines on the basis of revenues received and

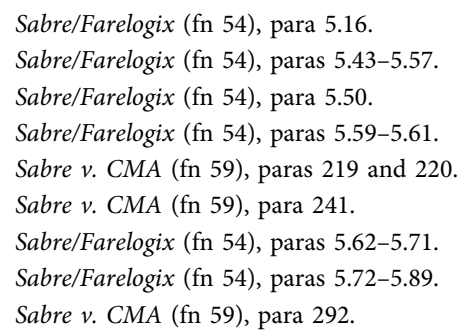

receivable for all providers of such services. ${ }^{92}$ It concluded that there was an increment (which it did not quantify precisely) in share as a result of the merger, as Farelogix 'derived value' from its supply of these services to British Airways and hence made a supply of them. ${ }^{93}$

The CAT held that, for the share of supply test to be satisfied, post-merger, either: (i) where neither party previously had a share of $25 \%$ or more, the merged entity must do so, or (ii) where one party previously had a share of $25 \%$ or more, its share must be increased, in either case as a result of the merger. ${ }^{94}$ The CMA has a discretion on the criterion, or criteria, that it uses to determine this. ${ }^{95}$ Having chosen them, it must apply the same criterion or criteria to both the merging parties and to other suppliers. ${ }^{96}$ The CAT was satisfied that the CMA had done so. ${ }^{97}$ In doing so, the CMA could take account of revenue received or receivable by Farelogix that was referrable to sales of tickets (62 in total) that included British Airways' interlining segments, even though this was paid by American Airlines in the United States and not by British Airways. ${ }^{98}$

Whilst, in principle, the CMA is required to quantify each party's share of supply, it was sufficient, on the facts of this case, for it to show that there was an increment in share of some real value, even if the CMA did not - or indeed, could not - quantify it precisely. ${ }^{99}$ This is because there is no 'de minimis' threshold in assessing the increment in the share of supply, provided that the increment has some numerical value. ${ }^{100}$ It was also sufficient that Farelogix had a contractual right to receive payment for the service supplied by it, irrespective of whether it had ever done so and whether it was economic for it to collect those fees. ${ }^{101}$ Where a party supplies the 'relevant description of services' as part of a wider service (here, Sabre's global reservation system) and does not levy a separate fee for it, it was not irrational for the CMA to use the total UK revenues for that wider service to calculate its share of supply. ${ }^{102}$

The CMA was also entitled to exclude certain thirdparty services from the 'relevant description of services' used to apply the share of supply test. In doing so, it must apply that definition consistently and coherently, which involves the exercise of evaluative judgement. ${ }^{103}$ It was, accordingly, not irrational of the CMA to exclude 
both suppliers whose activities were 'not comparable' to those of the parties and so fell outside the definition of the 'relevant description of services'104 and self-supplied services, as these do not constitute the supply of a service for the purposes of assessing jurisdiction, even if they might form part of the relevant market or constitute a competitive constraint on the merging parties. ${ }^{105}$

\subsection{Commentary}

The CAT's judgment in Sabre is an important one and provides guidance on how the CMA can apply the share of supply test. Its importance is, until there is a judgment of the Court of Appeal in another case challenging the CMA's application of the share of supply test, as great as that of the House of Lords in South Yorkshire Transport, ${ }^{106}$ concerning what is a 'substantial part of the United Kingdom' for the purposes of the share of supply test. Sabre has not sought permission to appeal the CAT's judgment. It will therefore be relied upon by the CMA as confirmation of the lawfulness of its expansive, even aggressive approach to asserting jurisdiction over mergers with even little nexus to the UK.

The CAT's judgment confirms the limits of a challenge to a CMA merger decision under section 120(4) of the EA 2002. As such a challenge is one of review, not an appeal on the merits, the CAT cannot substitute its own assessment for that of the CMA: to succeed, an applicant must identify either an error of law made by the CMA, procedural unfairness on its part, or that the decision is irrational, typically because it is not supported by a sufficient evidential foundation. ${ }^{107}$

Accordingly, challenging a finding of jurisdiction will be extremely difficult, particularly as the CAT has confirmed that the CMA has a significant discretion and margin of appreciation in applying the test, including in relation to: (i) identifying the relevant description of goods (or services) that it will use to assess shares of supply, (ii) the criterion or criteria that it will use to calculate those shares, and (iii) identifying which suppliers are, and are not supplying services within the 'relevant description of services' identified by it.

As well as confirming the CMA's broad discretion in applying the share of supply test, the CAT's judgment also confirms that, whilst there must be some overlap between the merging parties' activities, which can be determined on a functional basis (such that their products do not need to be identical, but merely perform

104 Sabre v. CMA (fn 59), paras 374 and 378

105 Sabre v. CMA (fn 59), para 384.

$106 R$ v. Monopolies and Mergers Commission, ex parte South Yorkshire Transport Ltd [1993] 1 W.L.R. 23. the same function for customers), the increment in the share of supply need not be large or significant and it can even be de minimis. It further confirms that a party may be found to be supplying goods or services in the United Kingdom even in circumstances where it does not have a direct contractual relationship with a customer in the UK and even where it does not receive payment from that customer.

The CMA has, therefore, effectively been given a 'green light' to apply the share of supply test pretty much as it - in its discretion - considers appropriate, subject only to the requirement that it has a sufficient evidential basis to support its decision that it has jurisdiction to review the merger and must apply consistently the criteria it selects for applying the test. Merging parties will find it very difficult to challenge the CMA, provided that there is some increment in market share (such that the post-merger 25\% threshold share of supply is met) and there is at least a limited 'UK nexus'.

Although, with Brexit, the CMA will now have jurisdiction to review more larger mergers that will satisfy the turnover test, the CMA will continue to routinely assert jurisdiction to review mergers where the target's UK turnover is below $£ 70$ million (or where it has no UK turnover at all), for example, where it is a new or potential entrant or is an SME active in a niche or local market. Therefore, the CAT's judgment will have considerable practical and commercial implications for merging parties.

\section{Conclusion}

The cases considered in this article, particularly Facebook and Sabre, provide further confirmation that the CMA has a broad discretion in exercising its powers under the mergers provisions of the EA 2002. Only where, as in JD Sports and FNZ, the CMA has failed to obtain sufficient evidence to support its findings or it has made a material factual error (e.g. in calculating market shares in finding an SLC or calculating shares of supply under the share of supply test) is a challenge to a finding of jurisdiction or an SLC likely to be successful.

The CAT's judgment in the pending appeal in Meta Platforms ${ }^{107 a}$ will provide further guidance on a number of important topics in merger control, including: the CMA's ability to take account of a loss of dynamic competition in finding an SLC; the determination of market

107 See e.g., O’Regan (fn 1), pp. 169-170 107a Meta Platforms v CMA (fn 53a) 
power; the determination of the counterfactual; disclosure of information during an investigation and the redaction of information from a final report after a Phase II investigation; the imposition of a divestiture remedy to remedy a vertical SLC; and the ability of the CMA impose additional requirements and conditions when imposing a divestiture remedy.

The judgments in Facebook and Sabre are particularly important for acquiring parties that choose to complete their merger before obtaining CMA clearance, both where they do submit a merger notice (either before or after closing) or they decide not to notify at all and the CMA opens an 'own initiative' investigation, whether because they consider that the CMA does not have jurisdiction to review their merger and/or because they consider that their merger will not result in an SLC. These judgments confirm that, in such cases, acquiring parties are running a considerable risk that the CMA will open an 'own initiative' investigation and impose a wide-ranging IEO that applies to both parties' entire global businesses. It is important to note that the CMA does not need to reach a definitive view on jurisdiction until the conclusion of a Phase 2 investigation ${ }^{108}$ and, indeed, as the CAT confirmed in Sabre may properly go through several iterations of the 'relevant description of services' it uses in applying the share of supply test, before alighting on a description that enables it to assert jurisdiction on the basis of a limited UK nexus and very small overlap.

The risks of CMA intervention in mergers therefore remains high, particularly where parties do not notify a merger voluntarily to the CMA and await clearance before closing. Given the CAT's confirmation that the CMA has a broad discretion in applying the share of supply test, and its powers both to impose IEOs and to require completed mergers to be unwound, will acquiring parties now increasingly make completion of their mergers conditional on receipt of CMA approval, leading to an increase in merger notifications to the CMA, even on a 'fail safe basis'? If they do not do so, acquiring parties run a considerable risk of an intrusive investigation that could result in the CMA asserting jurisdiction based on a definition of services that is not foreseeable, finding an SLC and requiring a completed merger to be unwound. 